\title{
Design of thioether cyclic peptide scaffolds with passive permeability and oral exposure
}

Andrei A. Golosov, ${ }^{\dagger,}$ Alec N. Flyer,,$+\neq$ Jakal Amin, ${ }^{\dagger}$ Charles Babu, ${ }^{\dagger}$ Christian Gampe,${ }^{\dagger}$ Jingzhou Li,${ }^{\dagger}$ Eugene Liu,,${ }^{\dagger}$ Katsumasa Nakajima, ${ }^{\dagger}$ David Nettleton,${ }^{\dagger}$ Tajesh J. Patel, ${ }^{\dagger}$ Patrick Reid,,${ }^{\S}$ Lihua Yang, ${ }^{\dagger}$ and Lauren G. Monovich ${ }^{\dagger, *, *}$

$\dagger$ Novartis Institutes for BioMedical Research, 181 Massachusetts Avenue, Cambridge, MA 02139

§PeptiDream, Inc., 3-25-23 Tonomachi, Kawasaki-Ku, Kanagawa JAPAN 210-0821

\section{SUPPORTING INFORMATION}

\section{TABLE OF CONTENTS}

Supplemental Figures

$\begin{array}{ll}\text { Supplemental Figure 1. } & \text { S2 }\end{array}$

$\begin{array}{ll}\text { Supplemental Figure 2. } & \text { S3 }\end{array}$

Supplemental Table 1. S3

$\begin{array}{ll}\text { Supplemental Figure 3. } & \text { S4 }\end{array}$

$\begin{array}{ll}\text { Supplemental Figure } 4 . & \text { S4-S11 }\end{array}$ 
Supplemental Figure 1. A plot of MDCK-LE $\mathrm{P}_{\text {app }}\left(\mathrm{x} 10^{-6} \mathrm{~cm}^{\cdot} \mathrm{s}^{-1}\right)$ vs. PAMPA $\log \mathrm{P}_{\text {app }}$ for the compounds described in the paper supports use of either permeability assay to identify compounds with high, medium, or low permeability.

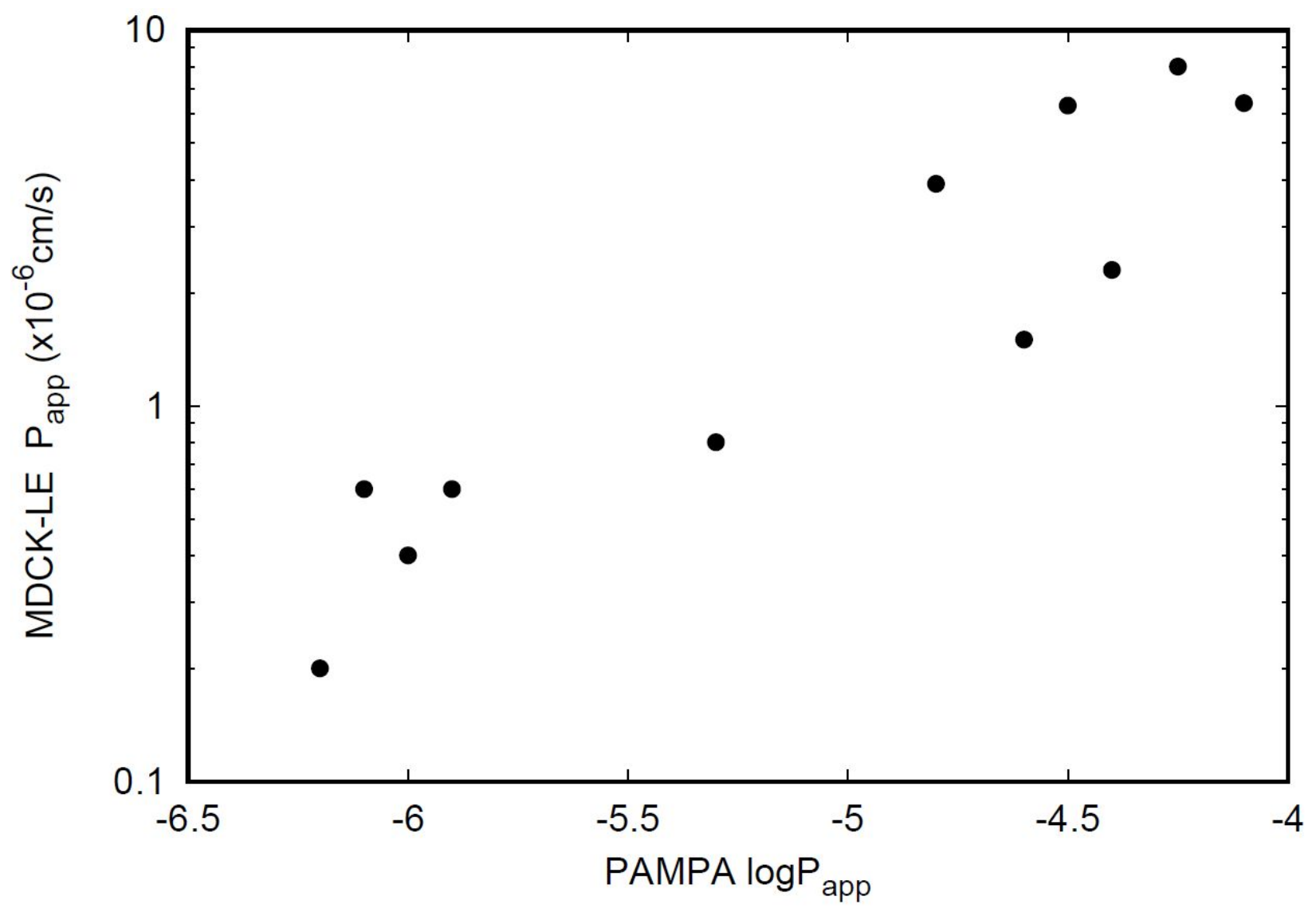


Supplemental Figure 2. A plot of measured $\log D$ vs. EPSA for the both compounds described in the paper plus additional macrocycles from the Novartis compound collection, suggests that permeable compounds have EPSA $\leq 80$ $\AA^{2}$ and fall within a preferred $\log \mathrm{D}$ range.

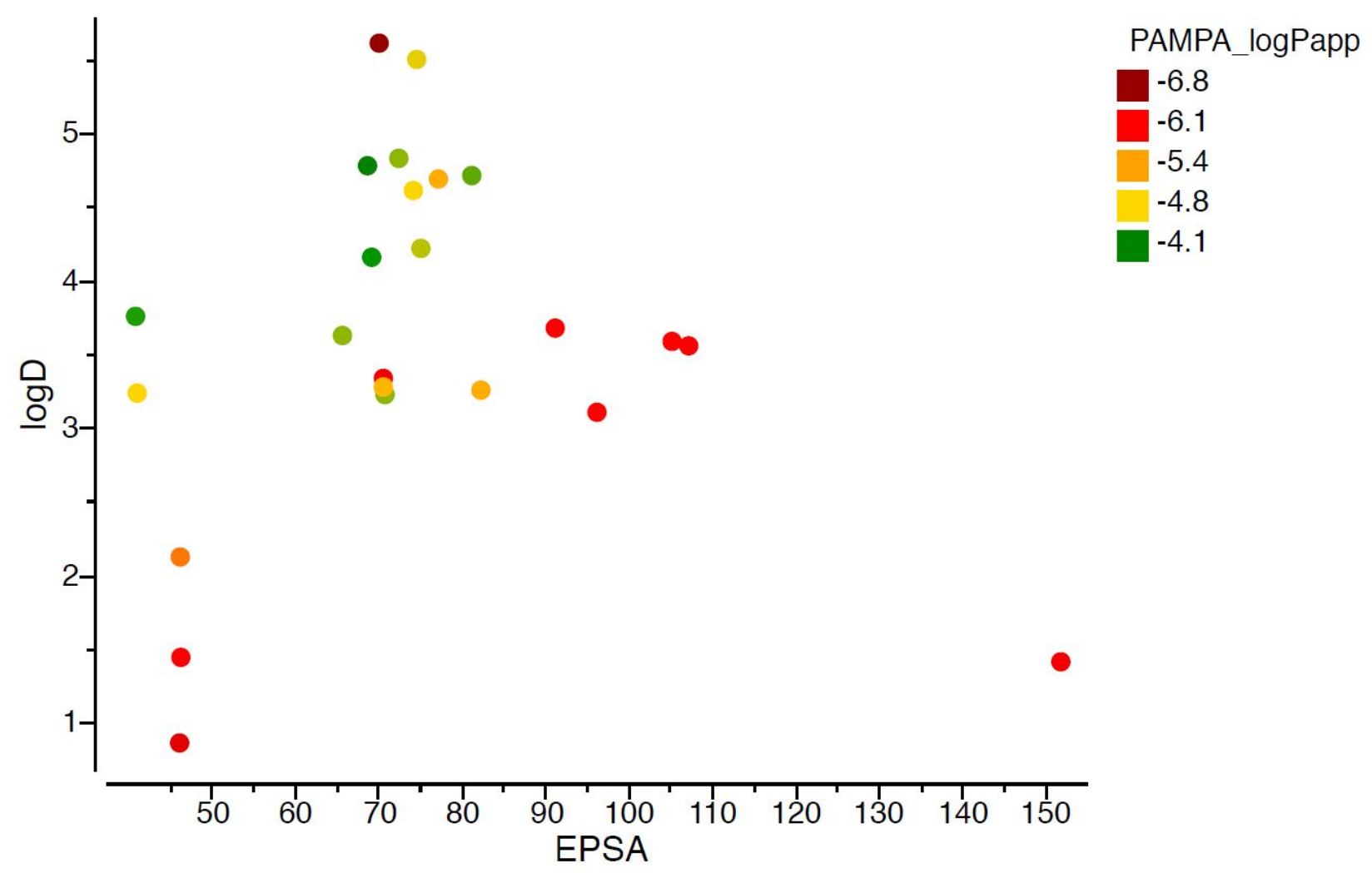

Supplemental Table 1. Table of Collected ROESY peaks

$\begin{array}{lllll} & \text { f2 }(\mathrm{ppm}) & \text { f1 }(\mathrm{ppm}) & \text { Flags } & \text { H atoms } \\ 1 & 7.5 & 6.42 & \text { Weak } & 1,34 \\ 2 & 5.06 & 2.87 & \text { Medium } & 11,15 \\ 3 & 4.41 & 3.41 & \text { Medium } & 19,21 \\ 4 & 7.16 & 5.06 & \text { Medium } & 22,11 \\ 5 & 5.06 & 3.12 & \text { Medium } & 11,46 \\ 6 & 7.23 & 5.06 & \text { Strong } & 31,11 \\ 7 & 4.41 & 2.31 & \text { Medium } & 19,15 \\ 8 & 7.5 & 4.91 & \text { Strong } & 1,3 \\ 9 & 4.88 & 3.12 & \text { Strong } & 7,46 \\ 10 & 4.91 & 4.85 & \text { Strong } & 3,35 \\ 11 & 4.41 & 3.01 & \text { Weak } & 19,47 \\ 12 & 7.16 & 4.72 & \text { Medium } & 22,24 \\ 13 & 4.41 & 2.86 & \text { Strong } & 19,15 \\ 14 & 7.16 & 4.41 & \text { Medium } & 22,24 \\ 15 & 7.08 & 2.31 & \text { Medium } & 53,15 \\ 16 & 7.08 & 3.42 & \text { Medium } & 53,21 \\ 17 & 7.16 & 7.51 & \text { Weak } & 22,1\end{array}$


Supplemental Figure 3. Atom labels for Compound 1a. Blue color indicates that chemical shift assignments were made for the corresponding hydrogens. Peptide bonds between atoms 16-18 and 5-28 are cis for both conformers in $\mathrm{CDCl}_{3}$ based on ROE $\mathrm{H} 15-\mathrm{H} 19$ and $\mathrm{H} 3-\mathrm{H} 35$ cross peaks.

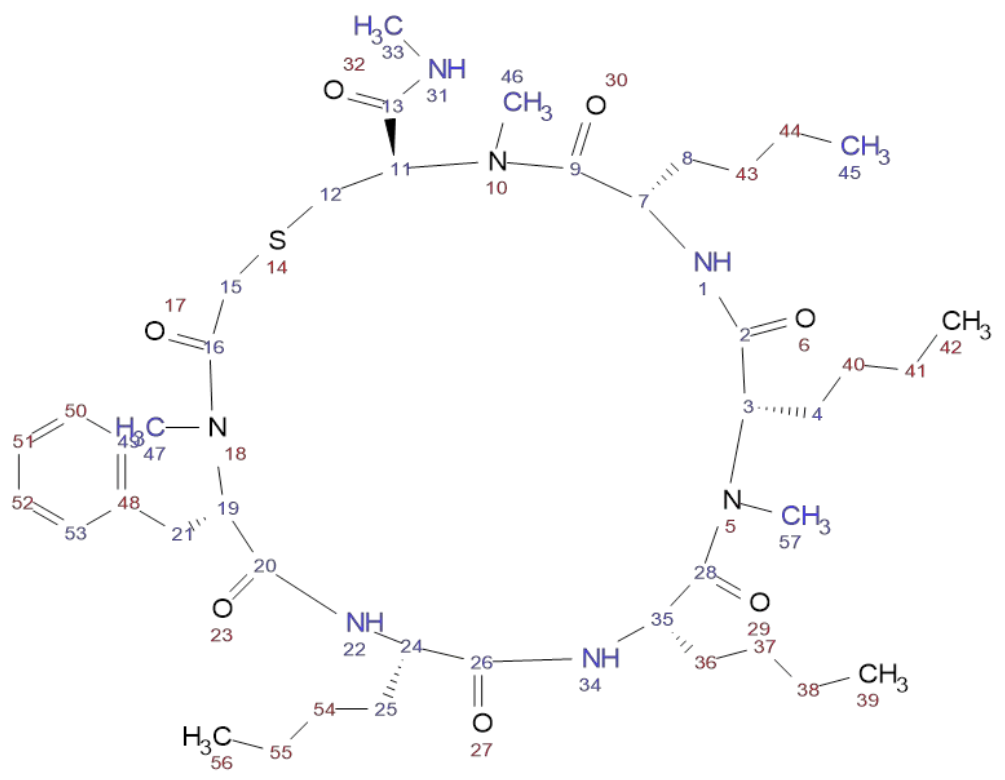

Supplemental Figure 4. Compound purity traces for all synthesized peptides. Purity was recorded as absorption at $214 \mathrm{~nm}$ unless otherwise noted in the table in the main text.

\section{Compound 1}

3: UV Detector: 214 Smooth (SG, 2x1)

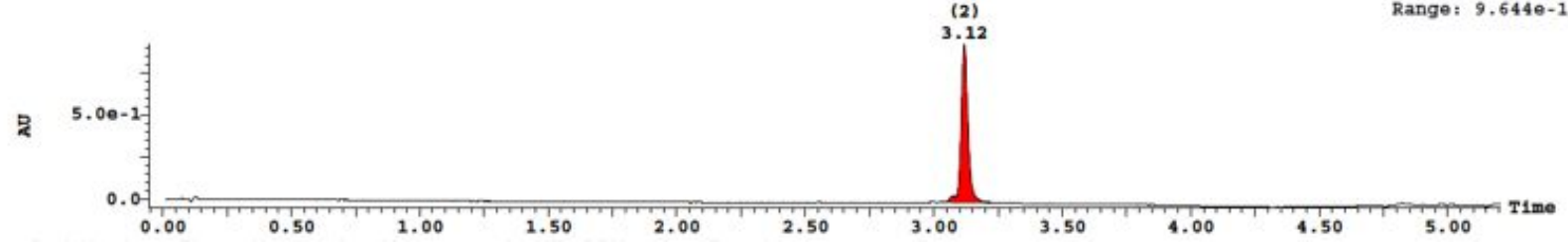

\section{Compound 1a}

3. UV Detector: 213.406_214.6 Smooth (SG, $2 \times 3$ )

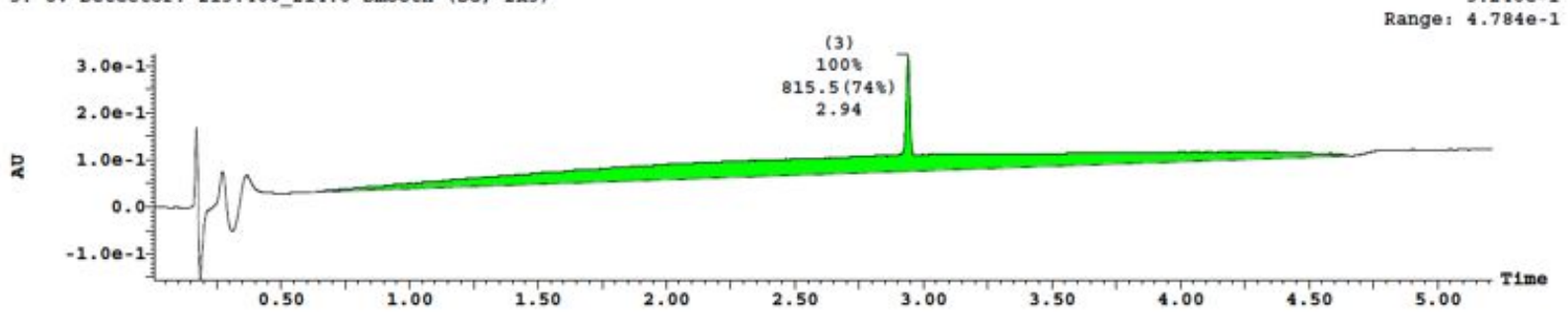




\section{Compound 1b}

3. UV Detector, 214 Smooth (SG, 3×2)

星

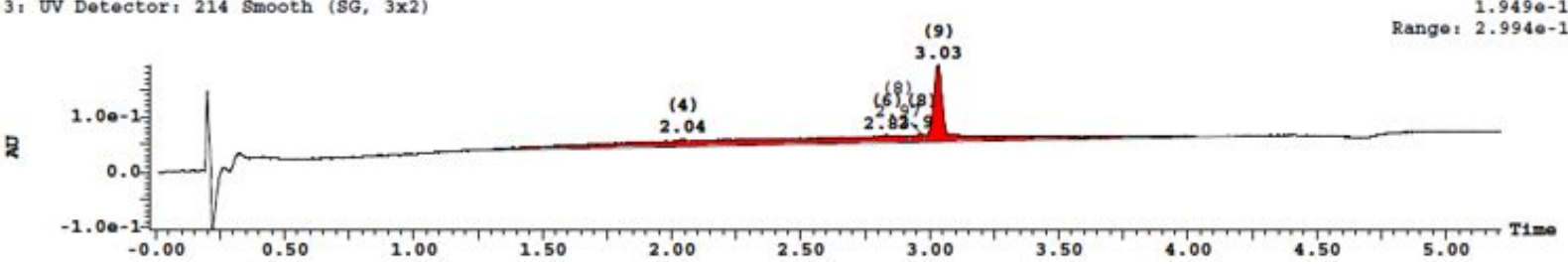

\section{Compound 2}

3: UV Detector: 214 smooth (SG, 2x2)

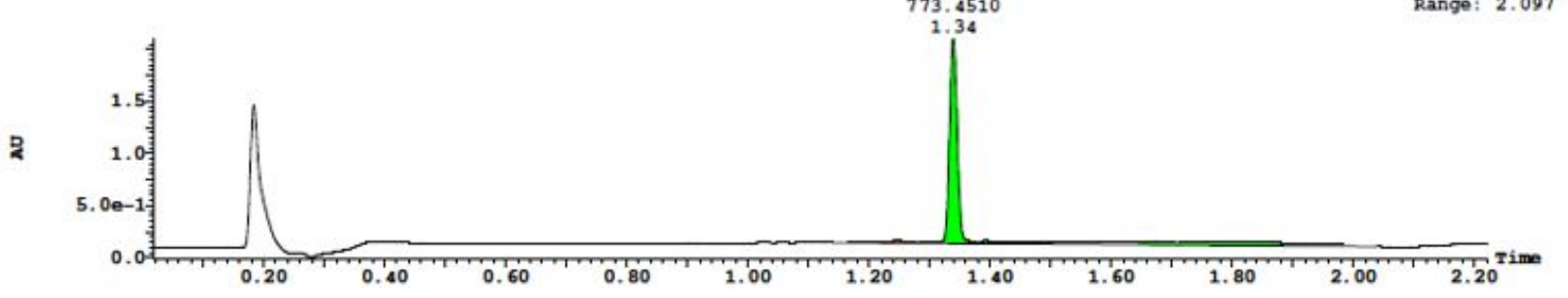

\section{Compound 2a}

3. UV Detector! 213.4_214.6 Smooth (SG, 2x3)

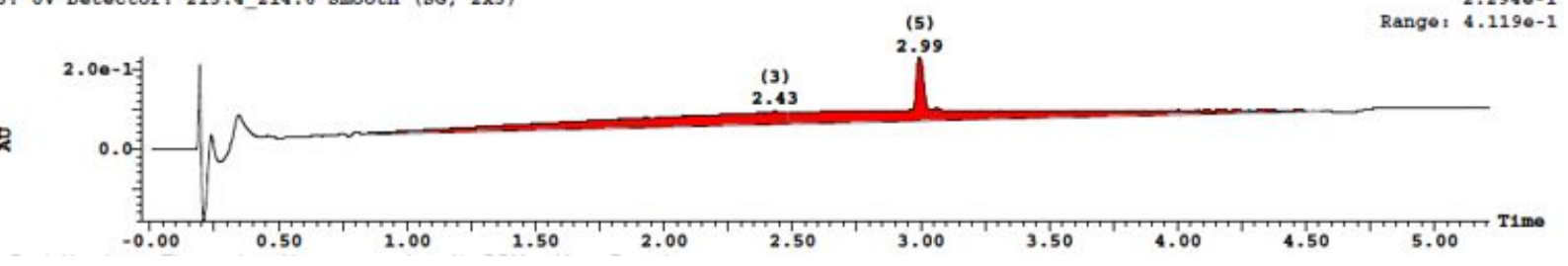

\section{Compound 2b}

3: UV Detector: 219.4_220.6 Smooth (SG, 2x3)

$1.096 e-2$

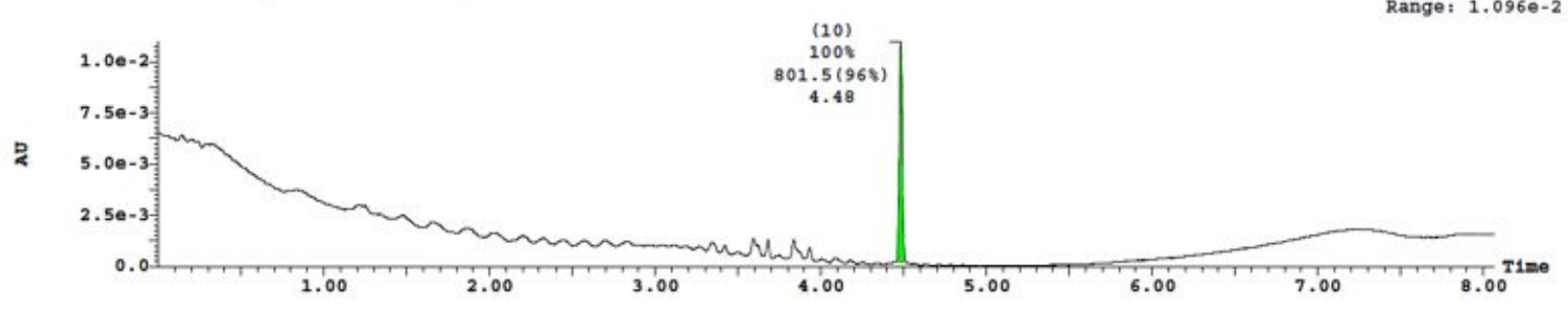




\section{Compound 2c}

(2) BLSD Smooth (SG, 2x3)

Range: 12

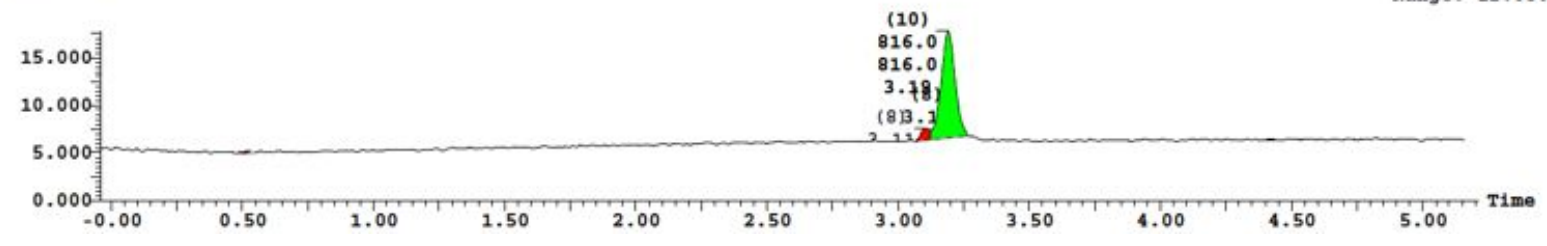

\section{Compound 2d}

3: UV Detector: 213.4_214.6 Smooth (SG, 3x2)

$8.73 e-1$

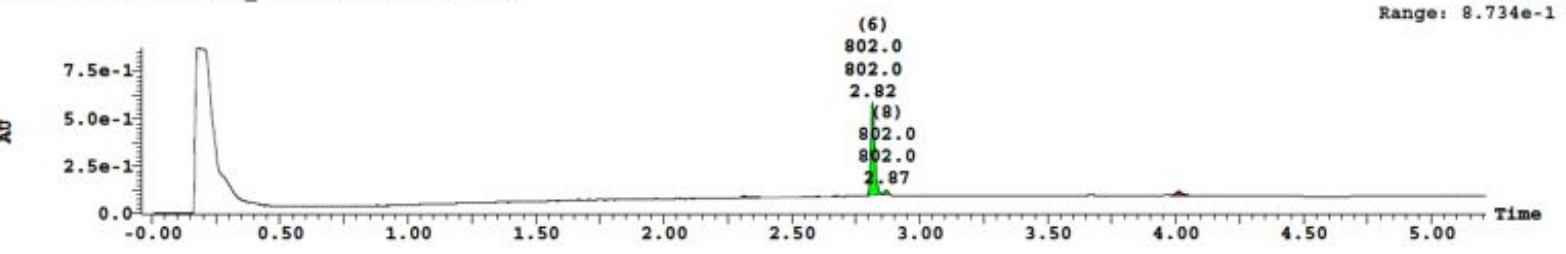

\section{Compound 2e}

3. UV Detector, 213.4_214.6 Smooth (8G, 3x2)

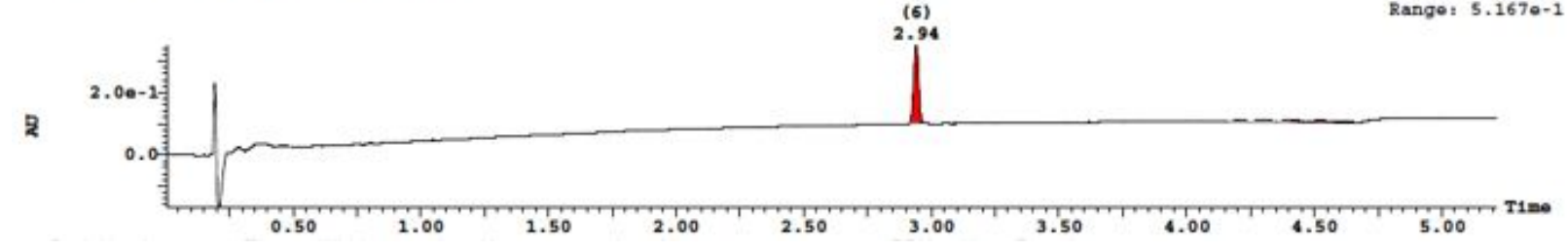

\section{Compound 3}

3: UV Detector: $107 \mathrm{Nm}$ Smooth (SG, 3×2)

운

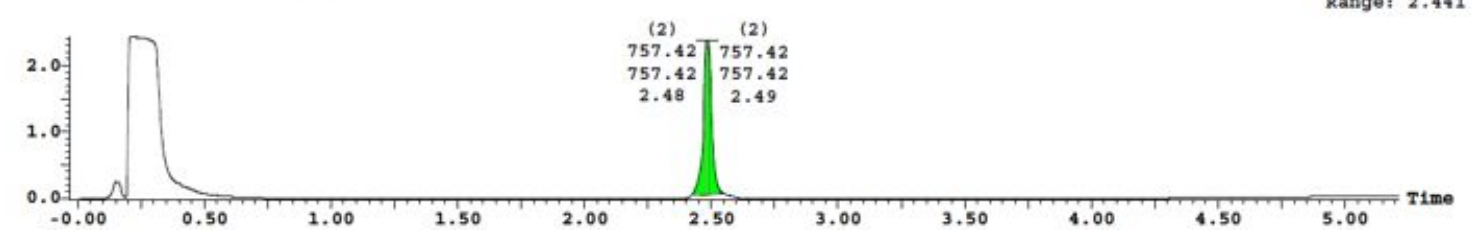




\section{Compound 3a}

2: UV Detector: 213.4_214.6 Smooth (SG, 2x3) 9.579e-1

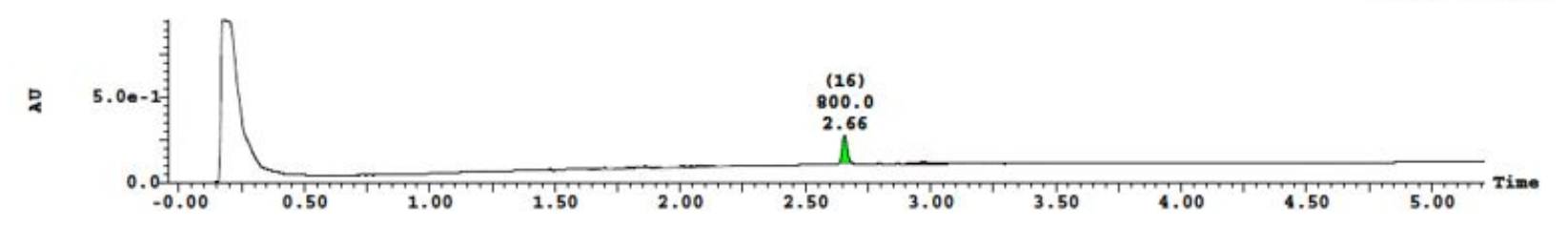

\section{Compound 4}

3. UV Detector: $107 \mathrm{Nm}$ Smooth (SG, 3×2)

Range: $\begin{array}{r}2.382 \\ 2.389\end{array}$

2

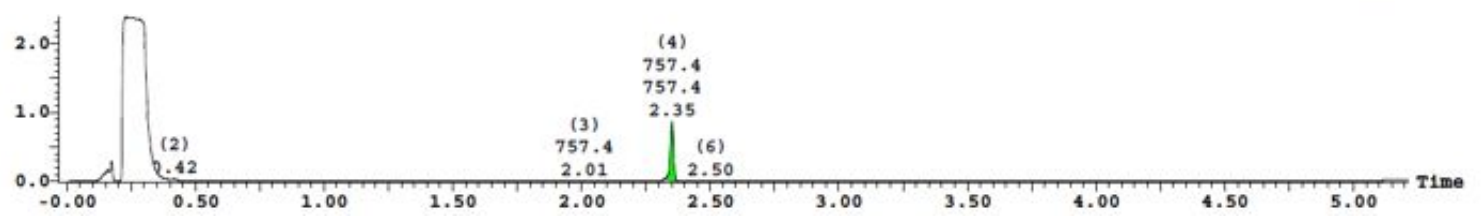

\section{Compound 4a}

3: UV Detector: 213.4_214.6 Smooth (SG, 2x3)

9.494e-1

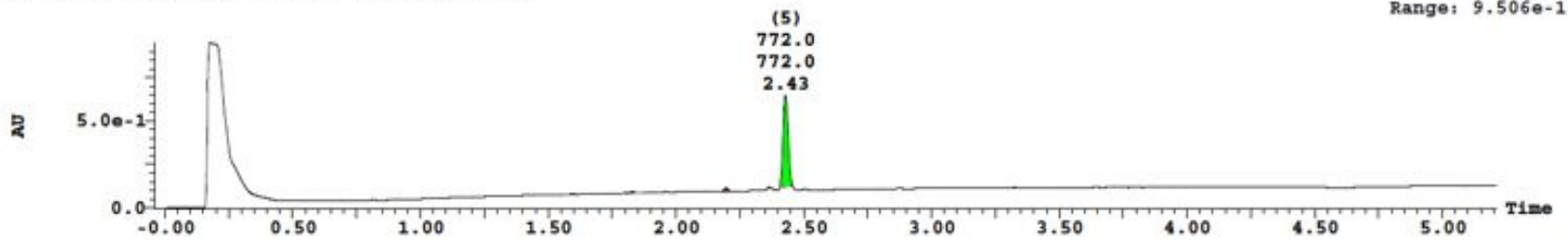

\section{Compound 5}

3: UV Detector: 213.4_214.6 Smooth (SG, 3x2)

Range, 1.082

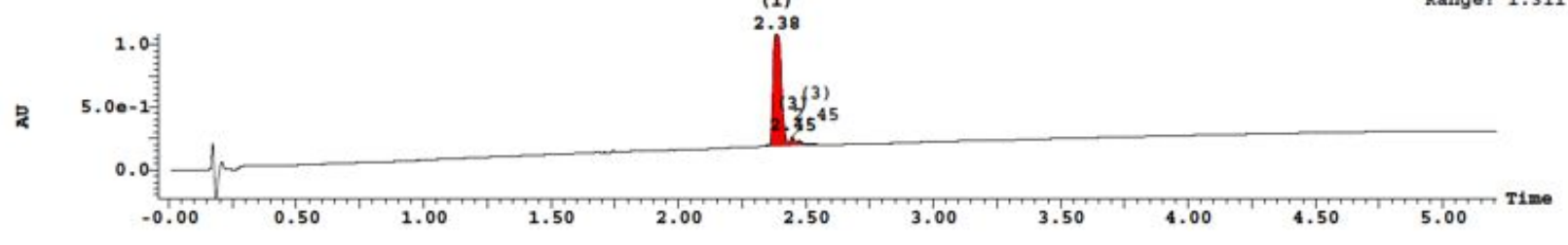




\section{Compound 5a}

2: UV Detector: $213.4 \_214.6$ Smooth (SG, $2 \times 3$ ) 9.587e-1
Range: $9.586 e-1 \quad$

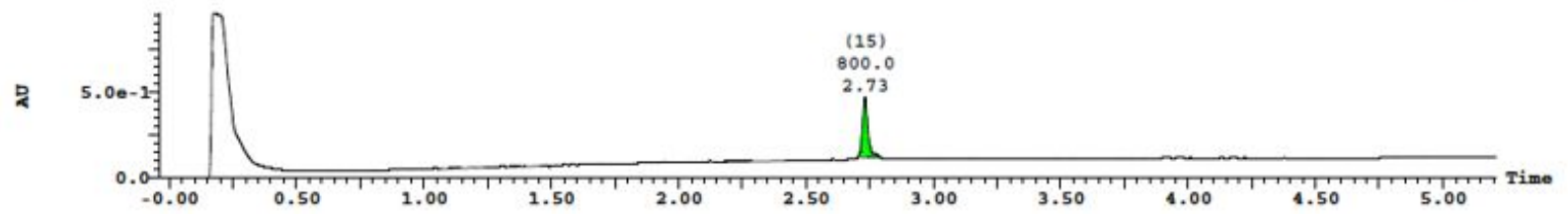

\section{Compound 6}

3: UV Detector: 214 Smooth (SG, 2xi)

1.193
Rango: 1.24

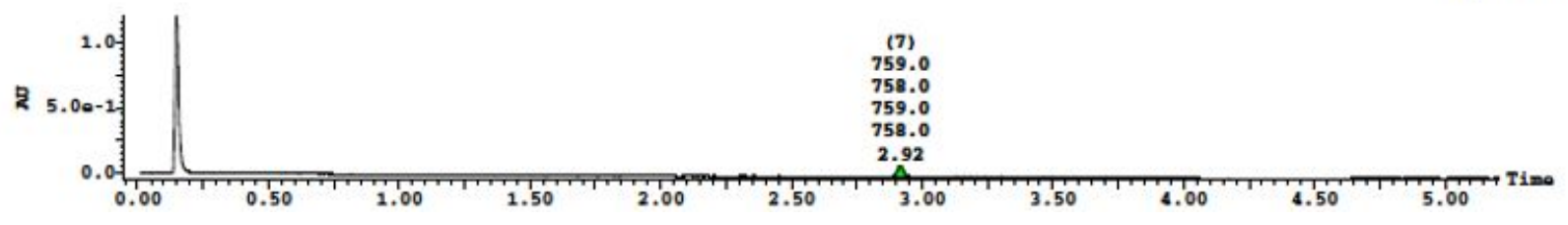

\section{Compound 6a}

2: UV Detector: 213.4_214.6 Smooth (so, 2x3)

Range: $\begin{array}{r}9.568 e-1 \\ 9.573 e-1\end{array}$

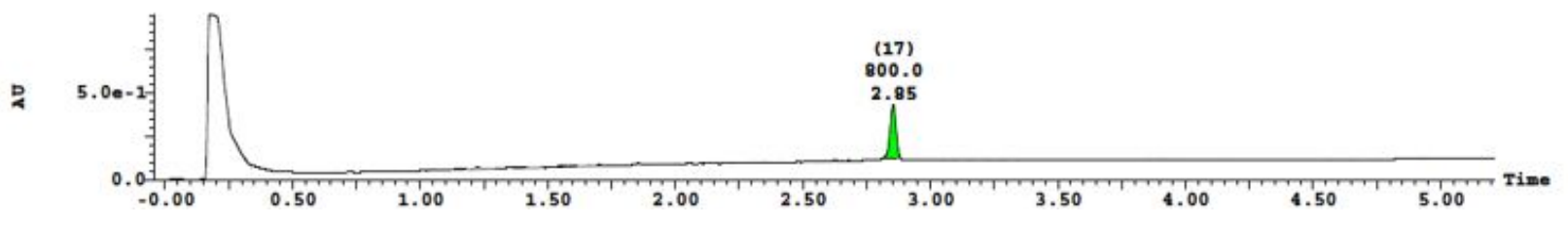

\section{Compound 7}

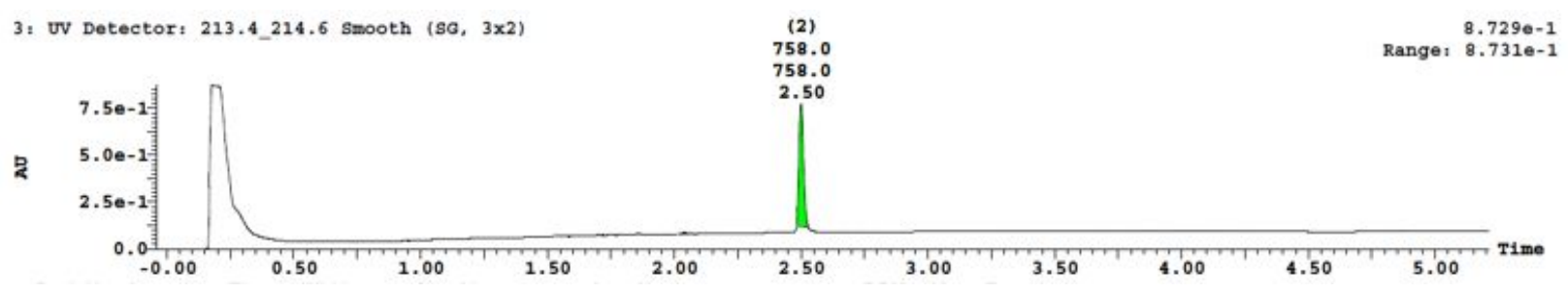




\section{Compound 7a}

3: UV Detector: 213.4_214.6 Smooth (SG, $2 \times 3$ )

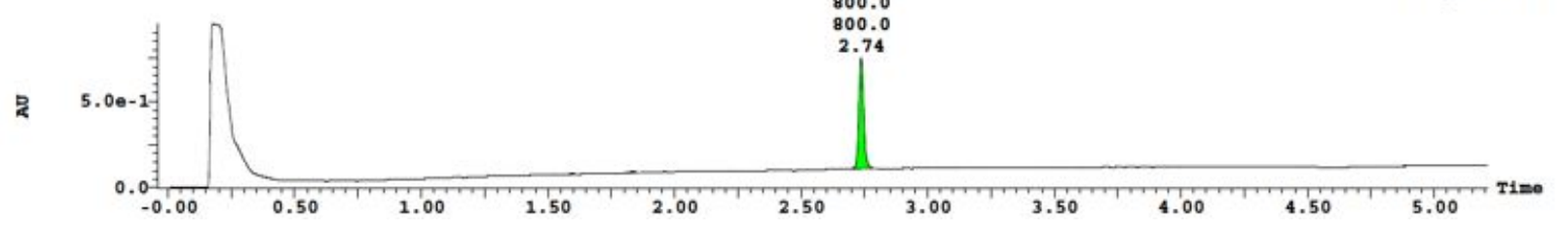

\section{Compound 8}

3: UV Detector: $214 \mathrm{Nm}$ Smooth (SG, 3×2)

Range: $\begin{array}{r}2.364 \\ 2.367\end{array}$

2

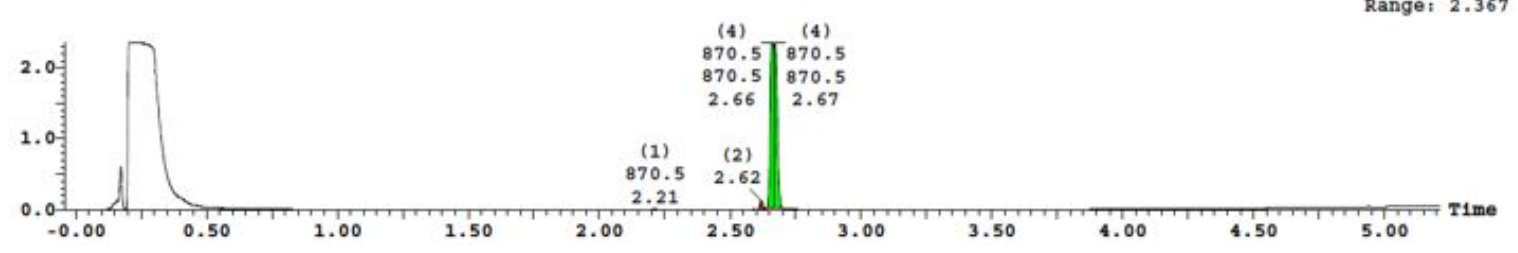

\section{Compound 8a}

(1) CAD Smooth ( $\mathrm{SG}, 3 \times 2$ )

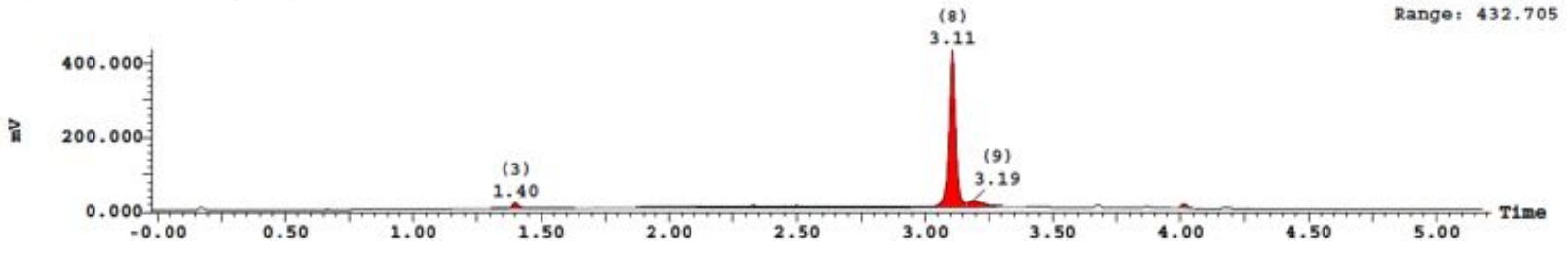

\section{Compound 8b}

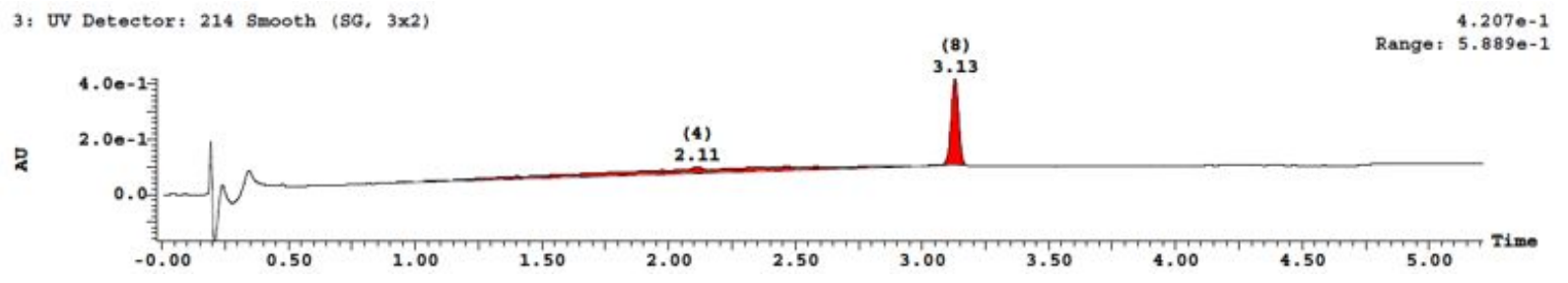




\section{Compound 8c}

3: UV Detector: 214 Smooth (SG, $2 \times 2$ )

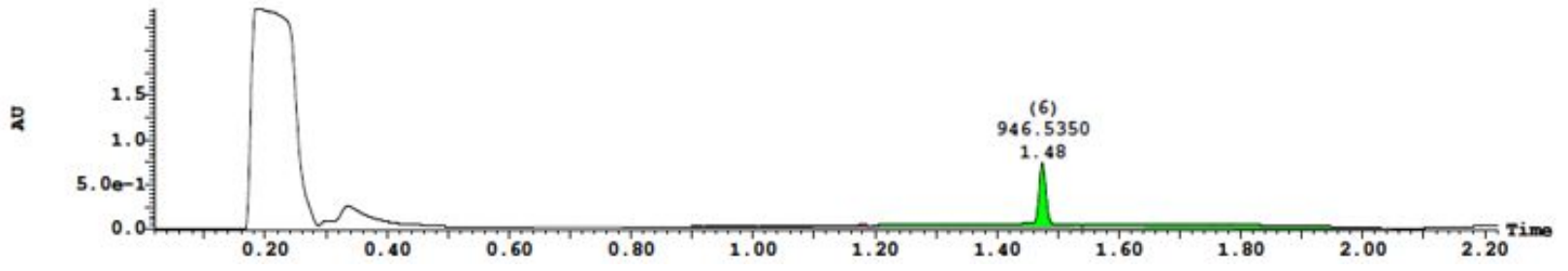

\section{Compound 9a}

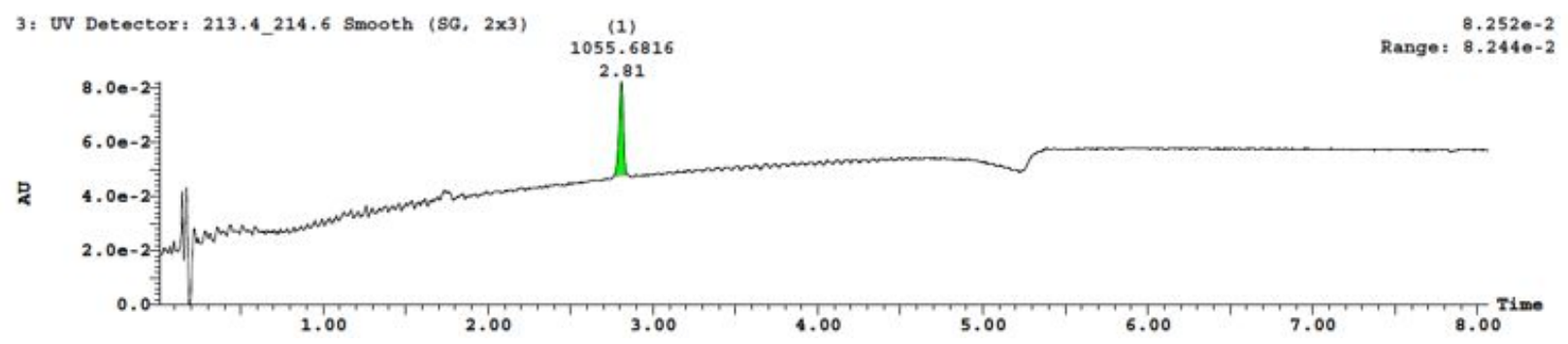

\section{Compound 10a}

3: UV Detector: 213.4_214.6 Smooth (SG, 2x3) $\quad$ (1) $1041.6660 \quad \begin{aligned} & 1.171 \mathrm{e}-1 \\ & 1.169 \mathrm{e}-1\end{aligned}$

\section{Compound 10b}

3: UV Detector: 214 Smooth (SG, 2x2)

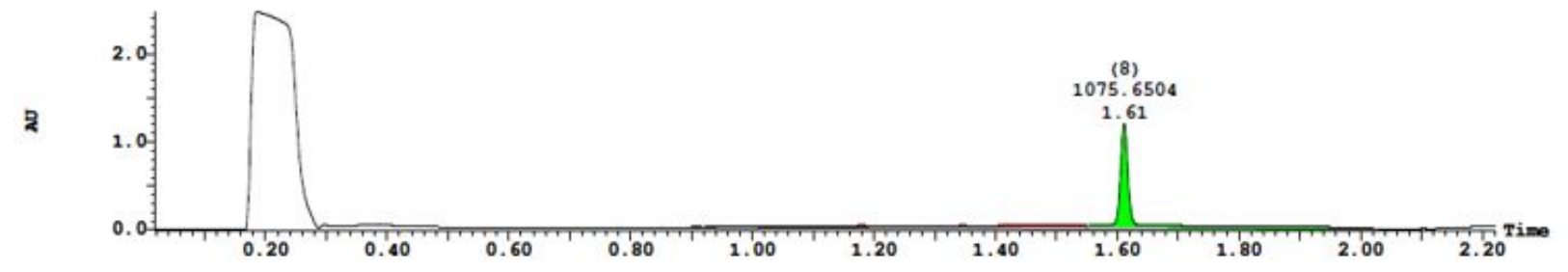




\section{Compound 10c}

3: UV Detector: 214 Smooth (SG, 2×2)

Range: $\begin{array}{r}2.465 \\ 2.465\end{array}$

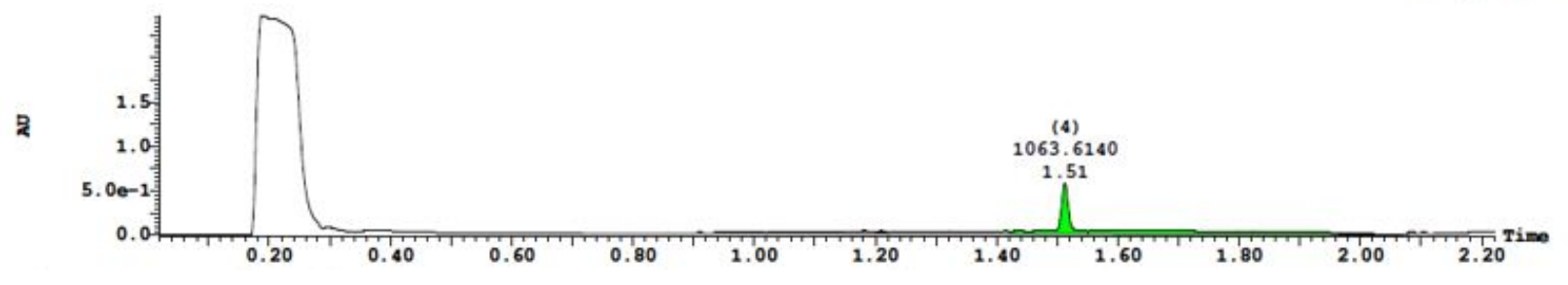

